\title{
BUEN VIVIR: UMA ALTERNATIVA LATINO-AMERICANA
}

\author{
BUEN VIVIR: A LATIN AMERICAN ALTERNATIVE \\ Luciana Costa Poli \\ UNESP - Universidade Estadual Paulista “Júlio Mesquita Filho" São Paulo - São Paulo- Brasil \\ Bruno Ferraz Hazan \\ Escola Superior Dom Helder Câmara - Belo Horizonte - Minas Gerais - Brasil
}

\begin{abstract}
RESUMO: O trabalho apresenta de forma sucinta algumas características do denominado constitucionalismo latino-americano, que se destaca pela tentativa de privilegiar a riqueza cultural e as tradições comunitárias e históricas na busca de uma refundação das instituições políticas e jurídicas. Esse movimento constitucionalista, como se pretende mostrar, ao incluir em sua agenda questões de cunho ambiental, social, econômico e jurídico tem acendido esperanças de que o desenvolvimento sustentável, fulcrado em uma nova visão do mundo, seria possível. A partir dessa visão, o artigo apresenta a noção do Sumak Kawsay (expressão de uma forma ancestral de ser e de estar no mundo) adotado pelo Plan Nacional para el Buen Vivir do Equador e por outros países como Bolívia e Venezuela, que propõe uma ruptura dos conceitos ortodoxos do desenvolvimento de hoje (crescimento, rapidez, exportação, dentre outros). O trabalho destaca a visão da natureza e do mundo expostas pelo Sumak Kawsay, como uma possível alternativa ao desenvolvimento sustentável. Aborda, ainda que de forma breve, algumas ideias do ecossocialismo e sua possível correlação com o Sumak Kawsay.
\end{abstract}

PALAVRAS-CHAVE: Sumak Kawsay; Buen Vivir; Constitucionalismo LatinoAmericano; Neoconstitucionalismo; Ecossocialismo.

ABSTRACT: The paper briefly presents some characteristics of the called Latin American constitutionalism, which stands out for trying to privilege the cultural richness and community and historical traditions in search of a refounding the political and legal institutions. This constitutionalist movement, as it is intended to show, when includes on its agenda issues of environmental, social, economic and legal nature has sparked hopes that the sustainable development, based in a new world view, would be possible. From this vision, the paper presents the notion of Sumak Kawsay (expression of an ancestral way of being and living in the world) adopted by the Plan Nacional para el Buen Vivir of Ecuador and other countries such as Bolivia and Venezuela, which proposes a rupture of the orthodox concepts of today's development (growth, speed, export, among others). The work highlights the view of nature and the world exposed by Sumak Kawsay, as a possible alternative to sustainable development. Discusses, even if briefly, some ideas of ecosocialism and its possible correlation with Sumak Kawsay.

KEYWORDS: Sumak Kawsay; Buen Vivir; Latin American Constitutionalism; Neoconstitutionalism; Ecosocialism. 


\section{Considerações iniciais}

A realidade latino-americana reclama uma premente quebra ou ruptura com a antiga matriz eurocêntrica de pensar o Direito e o Estado para o continente. Faz-se imperioso repensar e refundar as instituições políticas tradicionais, remodelando também os mecanismos jurídicos hábeis à satisfação dos interesses de parte da população que, tradicionalmente, sempre esteve alijada da vida política.

Alguns países da América Latina, tardiamente, parecem viver um fenômeno que desnuda as culturas nativas encobertadas e violentamente extirpadas da própria construção de sua história. Desenha-se assim um panorama de pretenso constitucionalismo emancipatório, preocupado também na concretização de políticas ambientais eficazes e consideradas necessárias ao desenvolvimento sustentável.

Esse constitucionalismo ecocêntrico latino-americano, de modo particular nos Andes, eleva os direitos da natureza (Pachamama) e da cultura do Bem Viver a status constitucional, positivando, a partir das reformas da Constituição do Equador em 2008 e da Bolívia em 2009, a prevalência da cultura da vida e a relação de interdependência entre os seres vivos, pautada no valor da harmonia e desdobrável em princípios como reciprocidade e complementaridade.

A partir deste novo paradigma, apresenta-se a proposta do Sumak Kawsay (Bem Viver) e sua cosmovisão, a enfrentar o atual desafio de articular e compatibilizar as macropolíticas ambientais, exigências do mandato ecológico, com as macropolíticas sociais, a minimizar as desigualdades sociais e regionais.

O modelo do Bem Viver, ainda em construção, configura-se como uma tentativa (ou crença) de que seria possível equacionar essas questões pela revisão da relação do ser humano com a natureza, pautando-se fundamentalmente no valor da harmonia, desdobrável em variáveis como, por exemplo, unidade, inclusão, solidariedade, reciprocidade, respeito, complementaridade e equilíbrio. 


\title{
2 Breves considerações sobre o constitucionalismo latino-americano
}

A sociedade contemporânea mostra-se dinâmica, multifacetária, apresenta demandas diversas, não é uniforme. Nessa perspectiva, o Direito e, especialmente, o Direito Constitucional apresenta novas perspectivas hermenêuticas na busca de projetos constitucionais mais progressivos, inclusivos, plurais. Fala-se, assim, em neoconstitucionalismo e até em neoconstitucionalismos (CUNHA, 2010, p. 247).

Sarmento (2010, p. 235) explica que é tarefa árdua definir o que seria o neoconstitucionalismo, mas segundo sua visão esse movimento trouxe mudanças de paradigma que implicaram no:

\begin{abstract}
a) reconhecimento da força normativa dos princípios jurídicos e valorização da sua importância no processo de aplicação do Direito; b) rejeição ao formalismo e recurso mais frequente a métodos ou "estilos" mais abertos de raciocínio jurídico: ponderação tópica, teorias da argumentação etc.; c) constitucionalização do Direito, com a irradiação das normas e valores constitucionais, sobretudo os relacionados aos direitos fundamentais, para todos os ramos do ordenamento; d) reaproximação entre o Direito e a Moral, com a penetração cada vez maior da Filosofia nos debates jurídicos; e) judicialização da politica e das relações sociais, com significado de poder da esfera do Legislativo e do Executivo para o poder Judiciário.
\end{abstract}

Certo é que a alguns países sul-americanos (em especial, Equador ${ }^{1}$, Bolívia e Venezuela), por meio de um novo movimento constitucionalista, tentam romper com a lógica liberal-individualista das constituições políticas herdadas da colonização europeia que, segundo Chivi Vargas (2009, p. 58), "tem sido historicamente insuficiente para explicar sociedades colonizadas; não teve clareza suficiente para explicar a ruptura com as metrópoles europeias e a continuidade de relações tipicamente coloniais em suas respectivas sociedades ao longo dos séculos XIX, XX e parte do XXI".

Trata-se de um processo de reinvenção do espaço público a ser construído tendo em vista os interesses e necessidades das maiorias até então

\footnotetext{
${ }^{1}$ A Constituição do Equador de 2008, além de ampliar e fortalecer os direitos coletivos (artigos 56 a 60: povos indígenas, afrodescendentes, comunais e costeiros), estabelece um inovador capítulo VII, que prescreve dispositivos (artigos 340 a 415) sobre o "regime de bem viver" e a "biodiversidade e recursos naturais", ou seja, sobre o que vem a ser denominado "direitos da natureza".
} 
excluídas dos processos decisórios. Adverte Dalmau (2008a, p. 22, tradução nossa) $)^{2}$ que:

\begin{abstract}
O desenvolvimento constitucional responde ao problema da necessidade. As principais mudanças constitucionais estão diretamente relacionadas com as necessidades da sociedade, as circunstâncias culturais, assim como o grau de percepção que essas sociedades possuem sobre as possibilidades de mudar suas condições de vida que, em geral, na América Latina não atendem expectativas esperadas com o transcorrer do tempo.
\end{abstract}

As constituições assim promulgadas constituem uma quebra ou ruptura com a antiga matriz eurocêntrica de pensar o Direito e o Estado para o continente. Procuram esses instrumentos repensar e refundar as próprias instituições políticas, remoldando os mecanismos jurídicos à satisfação dos interesses de parte da população que tradicionalmente não participava ativamente da vida política. É um fenômeno que desnuda as culturas nativas encobertadas e violentamente extirpadas da própria construção da história sul americana, em um movimento que tende a "descolonizar o poder e a justiça" (WOLKMER; FAGUNDES, 2011, p. 378).

Deve-se examinar o panorama desenhado por esse que vem a ser um constitucionalismo "novo", "emancipatório" ou "transformador" (DALMAU, 2008b, p. 69), no que se refere às inovações concernentes aos aspectos socioambientais, já que há, nesses instrumentos, uma preocupação de concretização de políticas ambientais eficazes consideradas necessárias ao desenvolvimento.

O novo constitucionalismo latino-americano é percebido, sobretudo, como um processo revelador do amadurecimento dos movimentos sociais e da conscientização da situação peculiar das comunidades. Não se caracteriza por formulações teóricas prévias e conformadas. Por isso, não constitui um sistema fechado, hermético, isolado ou de implementação de um determinado modelo constitucional rígido.

\footnotetext{
${ }^{2}$ La evolución constitucional responde al problema de la necesidad. Los grandes cambios constitucionales se relacionan directamente con las necesidades de la sociedad, con sus circunstancias culturales, y con el grado de percepción que estas sociedades posean sobre las posibilidades del cambio de sus condiciones de vida que, en general, en América Latina no cumplen con las expectativas esperadas en los tiempos que transcurren.
} 
A ausência de precisão teórica, outrossim, não inibe a identificação de traços comuns aptos a identificar o movimento. Sua orientação central refere-se à preocupação de trazer a lume a reflexão sobre a desigualdade social, seus impactos diretos e indiretos. Persegue-se a busca do bem viver e a proteção da dignidade humana. Em linhas gerais, propõe o rompimento da lógica liberalindividualista e eurocêntrica que orientou, de forma geral, as constituições latinoamericanas. Trata-se de uma possível reinvenção do espaço público, das políticas públicas e da participação popular.

Wolkmer e Fagundes (2011, p. 387) propõem três ciclos socais para compreender esse novo constitucionalismo emergente. São eles: (i) Um primeiro ciclo social de caráter descentralizador, previsto nas Constituições do Brasil de 1988 e Colômbia de 1991, ao qual talvez pudesse ser acrescentada a do Paraguai de 1992; (ii) Um segundo ciclo social orienta-se para um constitucionalismo participativo e pluralista do qual a Constituição da Venezuela de 1999 é o exemplo mais emblemático; (iii) O terceiro ciclo pode ser representado pela Constituição do Equador de 1998 e 2008 e da Bolívia de 2009, que expressam um constitucionalismo plurinacional comunitário no qual coexistem diversas sociedades interculturais, como a indígena, comunais, urbanas e camponesas.

Esse constitucionalismo latino-americano prioriza a riqueza cultural e as tradições comunitárias e históricas, busca a refundação das instituições políticas e jurídicas e pretende superar o modelo de política elitista. Para a concretização dessa meta de reinterpretação pluricultural, destaca a possibilidade de se acender o diálogo e a interculturalidade. Procura evitar, sobretudo, a sobreposição de culturas, para que não se repita a história, rica de episódios de predomínio selvagem da cultura europeia. É o que Santos (2010, p. 46) denomina "hermenêutica diatópica", com a qual operacionaliza as ideias centrais para esse novo movimento constitucionalista. Segundo o autor, a hermenêutica diatópica é um trabalho de interpretação entre duas ou mais culturas, com o objetivo de identificar preocupações isomórficas incluindo as diferentes respostas 
e fornecer um amplo campo de debates sobre os temas gerais do universalismo de renovação cultural (SANTOS, 2010, p. 46, tradução nossa) ${ }^{3}$.

Outra característica é a defesa pedagógica em favor ética da alteridade que, segundo Wolkmer e Fagundes (2011, p. 381), configura-se como a ética antropológica da solidariedade comprometida com a dignidade do outro. Persegue-se ainda a consolidação de processos conducentes à racionalidade emancipatória ${ }^{4}$ voltada à perseguição de interesses históricos, da expressão de uma identidade cultural própria a esses povos.

Nesse diapasão, as constituições da Colômbia, Bolívia e Equador já incorporaram o pluralismo jurídico e o direito de aplicação da justiça indígena como paralela à juridicidade estatal, reconhecendo a legitimidade da manifestação periférica de outro modelo de justiça e de legalidade, diferente daquele implantado e propalado como universal pelo Estado moderno. Relata Santos (2010, p. 91, tradução nossa) ${ }^{5}$ que no artigo 30, a Constituição da Bolívia estabeleceu vasta gama de direitos das nações e dos camponeses indígenas. É a expressão constitucional de correspondência pela primeira vez na história do país, entre a forte presença da população e da proeminência política dos povos indígenas. Dentre esses direitos está o direito à própria jurisdição, cujo escopo é definido nos artigos 190, 191 e 192. Na Constituição do Equador também são reconhecidos os direitos dos povos e nacionalidades indígenas (art. 57) e a jurisdição indígena (art. 171).

\footnotetext{
${ }^{3}$ La hermenéutica diatópica consiste en un trabajo de interpretación entre dos o másculturas con el objetivo de identificar preocupaciones isomórficas entre ellas y las diferentes respuestas que proporcionan.

${ }^{4}$ Apesar de a racionalidade ser uma característica essencial da natureza humana, que impulsiona ações individuais e sociais, compõe-se de significados diversos, sutis e implícitos, que influenciam e direcionam a visão de mundo da sociedade. A racionalidade emancipatória (direciona-se pela capacidade de homens e mulheres deliberarem sobre as condições da sua própria existência opõe-se à racionalidade instrumental ou funcional, chamada por Santos (2000, p. 123) de indolente (leva em consideração o cálculo utilitário de consequências como única referência a guiar à ações dos indivíduos que adquirem um sentido de comportamento racional limitado).

${ }_{5}^{5}$ En su artículo 30, la Constitución de Bolivia establecen vasto conjunto de derechos de las naciones y pueblos indígena originario campesinos. Es la expresión constitucional de la correspondencia, por primera vez en la historia del país, entre la fuerte presencia poblacional y el protagonismo político de los pueblos indígenas. Entre los derechos está el derecho a la jurisdicción propia cuyo ámbito queda definido en los artículos 190, 191 y 192. En la Constitución de Ecuador están igualmente reconocidos los derechos de los pueblos y nacionalidades indígenas (art. 57) y la jurisdicción indígena (art. 171).
} 
Esse movimento constitucionalista, ao incluir em sua agenda questões de cunho ambiental, social, econômico e jurídico tem acendido esperanças de que o desenvolvimento sustentável, fulcrado em uma nova visão do mundo, é possível.

Lançando novos olhares, a partir da compreensão da diversidade, esse movimento jurídico-político traz à lume novos sujeitos e institucionalidades. No reconhecimento de novos sujeitos, observa-se não apenas o reconhecimento das coletividades étnicas, mas o da natureza como titular de direitos. Isto porque, na perspectiva não dissociada entre ser humano e natureza, influenciados pelos valores indígenas, a Pachamama ganha titularidade jurídica. Acosta e Martínez (2009) informam que na Constituição do Equador (2008) a natureza ou Pachamama é reconhecida como um sujeito de direitos. Assim, a natureza teria o direito fundamental à vida, para manter seus ciclos evolutivos.

\section{Sumak Kawsay: uma forma alternativa de mobilização ou mais uma utopia política?}

Durante séculos, a América Latina parece ter adormecido, seguindo o ritmo imposto pelos resquícios de um colonialismo forte e sempre presente, embora muitas vezes, não aparente. Apesar de circunstâncias políticas, sociais e econômica adversas, qualquer movimento operário, estudantil ou de qualquer outra classe mostrou-se insuficiente para implementar uma radical mudança no panorama. Um círculo de rendição permanecia, enquanto a resignação parecia ter se instalado permanentemente.

Nesse cenário, surpreendentemente, discussões começaram a emergir dando azo a uma drástica ruptura. Debates constitucionais ocorridos na Bolívia e no Equador culminaram com uma proposta que repousa raízes na cultura de origem inca (kechwa) $)^{6}$, buscando articular-se a partir da concepção do paradigma do "viver bem" - em kechwa, sumak kawsay (BELLO, 2004).

Sumak kawsay é a expressão de uma forma ancestral de ser e de estar no mundo. Expressa, de certa maneira, as proposições teóricas de décroissance de

\footnotetext{
${ }^{6}$ É um idioma falado em alguns países andinos (particularmente no Peru, Equador e Bolívia), mas também no norte da Argentina e em outros países por um pequeno número de falantes (BENNETT, 1963).
} 
Latouche ${ }^{7}$, de convívio de Ivan Illich ${ }^{8}$ e de ecologia profunda de Arnold Naess ${ }^{9}$. O buen vivir relaciona-se às propostas de descolonização desenvolvidas por Quijano (1992), Santos (2004) e Lander (2005).

Sumak significa a plenitude, o sublime, excelente, magnífico. Kawsay refere-se à vida, em uma concepção dinâmica. Portanto sumak kawsay pode ser compreendido como a vida em plenitude. É a vida em excelência material e espiritual. O sublime expressa a harmonia, o equilíbrio interno e externo de uma comunidade (ACOSTA; MARTINEZ, 2009).

O conceito do sumak kawsay propõe uma oposição à lógica do capitalismo neoliberal que imprime uma concepção de vida boa atrelada à necessidade de consumir sempre mais e mais bens. Exaltar a convivência harmônica do homem e da natureza é um dos eixos centrais dessa proposta. O Plan Nacional para el Buen Vivir de 2009-2013 do Equador (EQUADOR, 2009) ${ }^{10}$, por exemplo, resume a adoção desse paradigma, ao propor uma ruptura conceitual dos conceitos ortodoxos do desenvolvimento de hoje (crescimento, rapidez, exportação, dentre outros). Propõe:

- Construir uma sociedade que reconheça a unidade na diversidade, admitindo a natureza gregária do homem.

- $\quad$ Promover igualdade, a integração social e a coesão como um guia para a vida.

- Garantir os direitos universais de forma progressiva e o fortalecimento das capacidades humanas.

- Construir relações sociais e econômicas em harmonia com a natureza.

- Saída à crise ideológica do capitalismo que surge a partir de uma conferência realizada pelo Institute for International Economics, em Washington, no ano de 1989.

- $\quad$ Fortalecer as relações de trabalho e de lazer libertadora.

- Reconstruir o público.

\footnotetext{
${ }^{7}$ Segundo Latouche (2004, p. 109), é preciso descolonizar nosso imaginário. Em especial, desistir do imaginário econômico [...] Redescobrir que a verdadeira riqueza consiste no pleno desenvolvimento das relações sociais de convívio em um mundo são, e que esse objetivo pode ser alcançado com serenidade, na frugalidade, na sobriedade, até mesmo em certa austeridade no consumo material. Sustenta que para salvar o planeta e assegurar um futuro aceitável para os nossos filhos, não basta moderar as tendências atuais. É preciso sair completamente do desenvolvimento e do economicismo.

${ }^{8}$ Com toques de radicalismo, afirma que a sociedade industrial promoveu uma nova elite de profissionais, cujo trabalho era convencer-nos de tudo o que "precisamos, não precisamos" (ILLICH, 1974. p. 22).

${ }_{9}$ Defende o valor intrínseco dos seres vivos, independentemente de sua utilidade instrumental às necessidades humanas. A ecologia profunda propõe que o mundo natural é um equilíbrio sutil de complexas inter-relações em que a existência de organismos é dependente da existência de outros dentro dos ecossistemas (NAESS, 1994, p. 120-124).

${ }^{10}$ Saliente-se que já há o Plan Nacional para el Buen Vivir de 2013-2017 (EQUADOR, 2013).
} 
- Aprofundar a construção de uma democracia representativa, participativa e deliberativa.

- Consolidar uma sociedade democrática, pluralista e secular.

Embora a noção do bem viver possa parecer apenas uma forma ingênua, embora harmônica, de convivência entre o ser humano e natureza, para Davalos (2005) é uma alternativa de combate ao modo capitalista de produção, distribuição e consumo, ao refletir uma postura de mobilização e resistência. Pode ser compreendida como uma relação peculiar entre a sociedade e a natureza, considerando as diversidades individuais, ao pregar o abandono da individualidade egoísta para a busca de uma consciência de responsabilidade social e comprometimento com o entorno natural.

O Sumak Kawsay compõe o discurso político dos movimentos indígenas da América equatoriana, a partir da recriação histórica de vivências ancestrais dos povos indígenas, principalmente no que se refere à construção de uma ética de socialidade e sua relação com a natureza. Pretende inaugurar uma nova pauta nos movimentos sociais de forma a fomentar a participação política das demandas indígenas em respeito ao multiculturalismo característico das Américas. Com propostas bastante particulares, propõe uma abertura para inserção dos diferentes modos de vida, o que se expressa, de certa forma, pelo seu projeto de Estado Plurinacional.

Procura-se consagrar as demandas dos direitos coletivos a partir de um giro de perspectiva, de forma a reconstruir um modelo de Estado capaz de incorporar as diferenças radicais que o constituem, abrindo caminhos para a aceitação de propostas de interculturalidade, promovendo o discurso efetivamente dialético entre toda a sociedade (ACOSTA, 2008).

A noção de Sumak Kawsay objetiva tornar a própria sociedade responsável e consciente pela maneira que cria e recria suas condições de existência. Busca a implementação de uma lógica pautada pela ética da alteridade, na qual as situações particulares não podem ser consideradas isoladas e dissociadas, pretendendo imiscuir a ideia de que constituem o interesse geral. O bem-estar de uma pessoa não se constrói sobrepondo-se ao dos demais, mas, sim, pelo respeito aos outros. 
Essa lógica parte para a constatação de que é necessária uma desconstrução das ideias dominantes sobre a economia, o crescimento econômico, a pobreza, dentre outras (EQUADOR, 2010). Pretende abandonar a própria percepção dominante de desenvolvimento, porque implica em violência, imposição, subordinação. Defende que não se pode "desenvolver" ninguém, se observados valores universais e não locais ou particulares, porque cada sociedade teria sua própria cosmovisão a ser respeitada. Propalar o desenvolvimento, se não observadas as particularidades, nuances, cultura e história de uma sociedade, implicaria em violência, uma interferência não promocional, e, portanto, que deveria ser repudiada.

A sociedade mercantil, segundo o movimento Sumak Kawsay, sempre atribuirá um valor à natureza e a converterá em parte de suas rendas, como se dela pudesse se apropriar. Ao mesmo tempo a natureza, tratada como objeto, torna-se o depósito de todos os seus desperdícios, sucatas, descartes e lixo porque não existe uma relação de respeito e consideração.

Na sociedade que se propõe essa noção de valor da natureza não existe, já que a natureza é parte da própria teia da vida que a compõe. O conceito de Sumak Kawsay permite exatamente isto: uma nova visão da natureza, sem ignorar os avanços tecnológicos nem os avanços em produtividade, mas projetando-os ao interior de um novo contrato com a natureza, em que a sociedade não se separa desta, nem a considera como algo externo ou como uma ameaça ou como o outro radical, senão como parte de sua própria dinâmica, como fundamento e condição de possibilidade de sua existência no futuro (ACOSTA; MARTINEZ, 2009).

O Sumak Kawsay pretende devolver à sociedade a forma pela qual se possa construir um tempo social fora da lógica da acumulação do capital, isto é, devolver aos seres humanos seu tempo pessoal e histórico, para que consigam viver plenamente suas vidas. Na lógica do capitalismo e da modernidade isso seria impossível. O tempo não pertence aos seres humanos. O tempo faz parte da acumulação do capital. Os seres humanos se resignam ao tempo do capital e sacrificam suas opções pessoais e seu tempo, porque este não lhes pertence (LEÓN, 2009). 
A partir do Sumak Kawsay seria possível problematizar o capitalismo e propor uma alternativa plausível e possível, inclusive de utilização do tempo. Um tempo que pertenceria à sociedade, permitindo que se construísse sem necessariamente hipotecar seu futuro na lógica da acumulação capitalista (EQUADOR, 2009).

Sem dúvidas, resgatar a historicidade dos povos latino-americanos, procurar equacionar as demandas e peculiaridades regionais, compatibilizandoas com um modelo de Estado inclusivo, participativo, que se preocupa com a inserção social da comunidade, é louvável. Incluir nessa pauta de discussão um modo de repensar a relação do homem com seu semelhante e, ainda, resgatar uma forma menos agressiva de convivência, proporcionando um ambiente mais saudável, é enobrecedor.

Não há como se negar que o homem contemporâneo iniciou uma jornada de reflexões e questionamentos em sua relação com a natureza, de forma a reconquistar uma estrutura de vida e ocupação dos espaços menos violenta. Certo é que os países da América Latina necessitam implementar políticas próprias de desenvolvimento que Ihes permitam desvencilhar de séculos de opressão e tentativas de uniformização.

\section{Desafios ideológicos para o desenvolvimento sustentável: ecossocialismo ou ecocapitalismo?}

Aceitando-se ou não as alternativas propostas pelo Sumak Kawsay, constatada a crise do sistema capitalista e suplantado o modelo de socialismo real, procuram-se novas soluções para o desenvolvimento, que perpassam por ajustes no modo de produção capitalista ou na busca de modelos alternativos. Certamente, as questões ambientais e o desenvolvimento sustentável reacendem de alguma forma os ideais socialistas, que vem sobre a denominação de ecossocialismo. Por outro lado, em percurso inicialmente antagônico, insurge um movimento ecocapitalista.

Não obstante os percursos distintos e a forma de realização de seus ideais, essas duas tendências não conseguem escapar a um objetivo comum: traçar metas para o desenvolvimento sustentável e fomentar ações pro ambiente: 


\begin{abstract}
O discurso do Desenvolvimento Sustentável ora serve para resgatar a funcionalidade do sistema capitalista, ratificando-o (eco-capitalista); ora para questionar sua estrutura propondo sua substituição (eco-socialista). Aos eco-capitalistas a expansão econômica é necessária, e pode estar em harmonia com a proteção ambiental. As soluções perpassariam três esferas: aprimoramento tecnológico, controle populacional e ajuda financeira aos países pobres (RIBEIRO e outros, 1993, p. 97).
\end{abstract}

Certo é que as possibilidades de desenvolvimento são particulares a cada região, a cada cidade, dificultando um discurso global e único. Um discurso hegemônico, por si só, é excludente e merece ser refutado. Nesse sentido, tentativas de uniformização e padronização de estruturas globais de desenvolvimento mostram-se ineficazes. Reflexões e debates enriquecem e possibilitam a construção de processos dialéticos de esclarecimento. Afinal, no mundo atual, reclamar para si a autenticidade de um discurso ecológico parece revelar um status (HERCULANO, 1992).

O capitalismo ecológico procura manter a essência dos ideais capitalistas que giram em torno da supervalorização do indivíduo e dos meios de aquisição de bens. O motor do processo produtivo e do próprio desenvolvimento sustentável, nessa concepção, permanece focado nas formas de acumulação de lucro, garantido mediante a produtividade e a concorrência (BOFF, 1999, p. 108).

Os ecocapitalistas coordenam suas ações para diminuir ou remediar os efeitos da crise ambiental, social, política e econômica, sem desenvolver questionamentos sobre as possíveis causas desse processo. Propõem procedimentos profiláticos e preocupam-se com os aspectos patológicos.

Layragues (1997, p. 10) defende a concepção de que o capitalismo ecológico funciona como um disfarce de determinadas correntes econômicas que pretendem propor um novo ajuste do sistema capital. No seu entender, essas correntes se propalam difundindo a ilusão de que se vive em tempos de mudanças, mas o desenvolvimento sustentável para esse movimento assume claramente a postura do projeto ecológico neoliberal, ainda que sob o signo de reformista:

Certo é que os critérios de eficiência econômica, orientados apenas pelas forças de mercado, não levam à redução de desigualdades sociais e regionais e ao uso racional dos recursos naturais. A referência à moldura ecológica da sustentabilidade tem sido até hoje mais retórica 
que efetiva; o governo é ainda dominado em seu núcleo central por uma visão clássica de desenvolvimento, a qual confere suprema importância, por exemplo, aos ministérios da fazenda, planejamento, transportes e energia, seguindo recomendações tradicionais dos conselheiros econômicos (CAVALCANTI, 1997, p. 33).

Diante da dificuldade de se resgatar o primado dos interesses sociais coletivos frente à perversidade da globalização econômica, deve-se questionar: o desenvolvimento sustentável e a preservação do meio ambiente são mitos insustentáveis?

Também, a par da angústia e do desafio do desenvolvimento sustentável, em sentido diametralmente oposto, com a queda do regime socialista e o aparente declínio da ideologia que Ihe sustenta, agarram-se alguns simpatizantes desse ideário a uma nova bandeira - a ecológica -, a qual se denominou de ecossocialismo. Inserem-se nesta corrente os marxistas ecológicos, os ecologistas sociais - verdes -, dentre outros (HERCULANO, 1992, p.15).

Economicamente, sua característica mais marcante refere-se à produção voltada para as necessidades e não para o lucro, sem agressão ao meio ambiente, privilegiando o bem comum em detrimento do enriquecimento individual.

Com o ruir do sonho socialista, seria a onda verde um novo contraponto ao sistema capitalista, ao buscar uma nova alternativa de sociedade e visão de mundo?

Inicialmente, a proposta parece interessante, mas não se pode olvidar que o Estado socialista não foi beneficente com o meio ambiente. Tanto o modelo de sociedade capitalista como o socialista romperam com a Terra e pretenderam sustentar um desenvolvimento calcado na massificação, autoritarismo, falta de participação e criatividade dos cidadãos. Ambos os sistemas privilegiaram o avanço técnico-científico, propalaram a uniformização, enquanto relegaram ao esquecimento a razão ética, refletiram o programa da modernidade, abafaram a diversidade e o multiculturalismo e promoveram a visão antropocêntrica.

Dentro dessa dualidade, o Sumak Kawsay se aproxima mais ao ideário ecossocialista, ao situar a pobreza, as condições de vida e a exclusão em um contexto político que não pode ser resolvido a partir da lógica do homo 
economicus $^{11}$. Isso porque, à medida que se incrementa a renda econômica, incrementa-se seu desejo de consumir sem levar em consideração a natureza, a ética e a sociedade. Propõe uma alternativa ao desenvolvimento, que seria dotado não dos mesmos instrumentos do capitalismo, mas sim com propostas diversas, uma lógica e uma sistemática diferentes, mas que, sobretudo, pretende redirecionar as relações sociais e as relações do homem com a natureza, almejando a construção de um ambiente mais saudável.

\title{
5 Utopia ou não: em busca de uma caminho
}

Utopia ou não, parcela considerável da humanidade anseia por um modelo de desenvolvimento diferente daquele que está posto. Conforme afirma o poema de Galeano (1994, p. 310, tradução nossa) $)^{12}$, a utopia faz avançar:

\begin{abstract}
A utopia [...] está lá no horizonte. Aproximo-me dois passos, ela se afasta dois passos. Caminho dez passos e o horizonte corre dez passos. Por mais que eu caminhe, jamais alcançarei. Para que serve a utopia? Serve para isso: para que eu não deixe de caminhar.
\end{abstract}

A narrativa do escritor uruguaio exprime com perspicácia, ironia e rara lucidez episódios da história latino-americana. Sua literatura visceral descreve a graça e a desgraça da riqueza das Américas, a fúria imperialista, a prosperidade do colonizador arrancada dessas terras e a benevolência dos nativos, de certa forma perpetuada até hoje pela avassaladora opressão cultural impingida pela força do ideário europeu ${ }^{13}$.

O historiador Hobsbawm (1980, p. 65) assinala que o século XX marcou o fim de sete mil anos de vida humana centrada na agricultura, desde que apareceram os primeiros cultivos, no final do paleolítico. A população mundial tornou-se urbana e os camponeses tornaram-se cidadãos. Na América Latina, o

${ }^{11}$ O homo economicus, ou homem econômico, é o conceito segundo o qual o homem é um ser racional, perfeitamente informado e centrado em si próprio, um ser que deseja riqueza, evita trabalho desnecessário e tem a capacidade de decidir de forma a atingir esses objetivos. $O$ homem econômico é, portanto, um ser idealizado, utilizado em muitas teorias económicas (BARRACHO, 2001, p. 34).

${ }^{12}$ Utopia [...] ella está en el horizonte. Me acerco dos pasos, ella se aleja dos pasos. Camino diez pasos y el horizonte se corre diez pasos más allá. Por mucho que yo camine, nunca la alcanzaré. Para que sirve la utopia? Para eso sirve: para caminar.

${ }^{13}$ Sobre o assunto, Galeano (2001). 
processo acompanha essa tendência: crescimento descontrolado das cidades e usurpação desmedida dos recursos naturais.

Para Thielen (1998), a crise atual está enraizada nos princípios da modernidade. A atual fase do capitalismo apresenta-se totalitarista, concentradora de riquezas e promotora da exclusão humana, já que o socialismo, como não foi inclusivo, nunca foi real. Na sua visão, os dois sistemas são perversos porque estabelecem como figura central o Estado e não o indivíduo. Nesse raciocínio, a própria perversidade do capitalismo causará a sua própria ruína. Afirma Vizentini (1998, p. 214) que o capitalismo revela-se incapaz de estabelecer uma resposta globalmente integradora e estável, e o neoliberalismo agrava ainda mais esse quadro burlesco tornando-se uma espécie de suicídio para o próprio sistema.

Não obstante, o Sumak Kawsay pode ser identificado como um movimento ecossocialista ao refletir importância em recuperar os interesses sociais e coletivos, agregando-os aos interesses do destino comum da humanidade e do planeta. Para tanto, conclama-se o resgate de princípios, como da solidariedade (com os pobres, com os povos e com as gerações futuras); da diversidade (cultural e biológica); da igualdade (de condições); da liberdade (para expressar as virtudes); da participação (nas decisões políticas); e, ainda, a religação do ser humano com o sentimento profundo da criação.

A proposição do novo ainda não realizado remete a princípios, sonhos, concepções e ao resgate dos utopistas. Há a busca por um interesse comum, pelo mesmo sonho, por um lugar ideal ou um espaço ideal, uma nova sociedade. Uma sociedade que passa a repudiar a visão da natureza como um reservatório de matérias primas à disposição dos homens. A busca da alteridade, de uma relação harmônica com as demais criaturas e com a natureza ${ }^{14}$ parece descortinar novos horizontes.

Requer-se uma mudança de estado, já que os pilares da sociedade contemporânea ainda repousam na uniformização (WALLERSTEIN, 2006, p. 146), característica fundamental do estado moderno, que nega sistematicamente

\footnotetext{
${ }^{14} \mathrm{O}$ ser humano colocou-se numa posição central diante da natureza. "Tudo culmina nele. Nada tem valor intrínseco, nada possui alteridade e sentido sem ele. Todos os seres estão a seu dispor para realizar seus desejos e projetos. São sua propriedade e domínio. Obcecado pelos lucros imediatos, o homem já não vive mais com as criaturas, mas atua sobre elas e contra elas" (BOFF, 1999, p. 112).
} 
a diversidade e outras formas de enxergar o mundo. Vive-se um momento de mudança de época e de crise das instituições modernas, por isso a luta pelo reconhecimento da modernidade é ainda difícil. A diversidade é ocultada para estabelecer-se um padrão, que se opera por um encobrimento de outras formas de pensar e compreender o mundo, fixando-se numa hegemonia filosófica e cultural europeia.

A imposição da hegemonia abafa os costumes locais e encobre as diversidades sob um falso manto de proteção (museificação). A justificativa de intervenção em nome da evangelização e civilização dos direitos humanos acaba por destruir e moldar o pensamento a um só standart.

A ideia do Sumak Kawsay pode significar a aproximação de uma nova era, na medida em que evidencia o reconhecimento de um direito à diversidade, sem padrão normalizador, de forma não hierarquizada, na qual os diversos grupos passam a compartilhar o mesmo espaço, um espaço dialógico de inclusão. Fomenta o culturalismo em oposição à universalização.

O constitucionalismo latino-americano, em especial da Bolívia, Equador e Venezuela cria um espaço comum de construção de direitos fundamentais de forma dialógica. Rompendo com a lógica do sistema moderno, pretende implementar uma nova ordem comunitária na América. Mas a formação de identidade nacional não será sempre uma invenção? (HOBSBAWM, 1983). Não obstante, o movimento neoconstitucionalista latino-americano, ao discutir os mitos da modernidade, pode estar a demonstrar que se começa a romper, lenta e pontualmente, na contemporaneidade, o universalismo europeu.

Santos (2004, p. 78) salienta que o enfrentamento dos mitos modernos ajuda a compreender as bases das sociedades de exploração de recursos e pessoas. Segundo o autor, esses mitos sustentam a exploração da riqueza das Américas pelos invasores europeus que não consideram os selvagens (os povos originários) como pessoas. A separação do homem da natureza é um dos fundamentos ideológicos do sistema que perdura até hoje: a natureza, vista como algo separado dos seres racionais, serve para ser explorada pelos homens, abastecendo a sociedade e sua indústria de todos os recursos que necessitarem.

Revisitar o Sumak Kawsay é buscar compreender a natureza sob uma ótica sistêmica, estabelecendo um horizonte ainda de difícil compreensão, na 
medida em que se acostumou a ver e a entender as relações entre humanos e natureza sob um enfoque monocular, no qual o homem dela se distingue agindo sobre ou através dela, modificando-a.

O Sumak Kawsay mostra que nem sempre o homem enxergou a natureza com o mesmo significado. Para os povos nativos da América, a natureza era vista e entendida como um processo sistêmico e dinâmico, no qual cada mineral, rocha, ar, ser vivo e o sobrenatural eram considerados fundamentais para a constituição e preservação do todo existente.

Percebe-se que é o contexto histórico e espacial de cada época que determina o tipo de visão que se estabelece da natureza. Para se atingir um espectro mais amplo, faz-se necessário perceber a natureza na sua dinâmica integradora. Por outro lado, também se deve ter o cuidado de não rechaçar as mais diversas contribuições possíveis para não se estabelecer apenas uma visão holística.

Uma compreensão meramente holística, segundo Guattari (1989, p. 23), seria totalizante e excludente. Por isso, deve-se visar a articulação entre três registros ecológicos: o do meio ambiente, o das relações sociais e o da subjetividade humana, buscando-se, assim, uma visão "ético-política". Dessa maneira, o todo poderá ser visto como o conjunto das partes interconectadas, resgatando a visão da diferença. O todo que une sem tornar idêntico o dessemelhante (SANTOS, 2004, p. 89).

Certo é que todo esforço criativo de pensamento é salutar para dar conta da complexidade das sociedades contemporâneas, de forma a conciliar a confluência de toda a diversidade. Um dos maiores males da atualidade é a escassez de pensamento. A crise atual é profunda e coloca em cheque a legitimidade das instituições, não apenas do exercício do poder, mas dos princípios que o sustentam.

Espera-se que o resgate e a inserção de novos ou abafados pensamentos, como o Sumak Kawsay, sejam capazes de oxigenar as bases sócio-filosóficas da América Latina. Isso poderia significar o abandono dos pilares de racionalidade instrumental da modernidade, cominando uma verdadeira transação civilizacional a configurar a autonomia construída a partir da historicidade. A incerteza faz 
parte do processo, já que crises e flutuações costumam entoar uma virada epistemológica:

\begin{abstract}
A lição para a epistemologia é esta: não trabalhar com conceitos estáveis. Não eliminar a contra-indução. Não se deixar seduzir pensando que finalmente encontramos a descrição correta "dos fatos", quando tudo o que tem acontecido é que algumas novas categorias foram adaptadas a algumas velhas formas de pensamento, as quais são tão familiares que tomamos seus contornos pelos contornos do próprio mundo (FEYERABEND, 1981, p. 40, tradução nossa) ${ }^{15}$.
\end{abstract}

\title{
6 Considerações finais
}

A relação homem-natureza é um dos pontos centrais do problema ético enfrentado na atualidade. $O$ surgimento de pensamentos, teorias e modelos que buscam revisitar e compreender os pilares da civilização e sua relação com o entorno confluem em diversos caminhos. Uma vez mais a humanidade assustase na encruzilhada recorrente entre Eros e Tanatos. São várias interseções possíveis, mas a eclosão de movimentos ecocêntricos, ainda que em processo gestacional de teorização e fundamentação, parecem indicar que não há como assegurar a vida e o futuro para todos os seres vivos, sem que se implemente, de modo contundente, uma reversão na forma de enxergar o planeta.

$\mathrm{Na}$ América Latina, ainda sufocada por valores universais eurocêntricos, sob a ameaça de um colapso social e ambiental, começa a se delinear uma nova visão de mundo, orientada pelo Bem Viver.

Com essa nova perspectiva, a partir da compreensão de que a natureza é um todo orgânico e inter-relacionado na qual gira a humanidade, ressurge a esperança ou a tentativa de ressignificar-se a relação da humanidade com o planeta terra e de implementar-se um modelo socioambiental comunitário e solidário.

Nesse sentido, os ideais do Sumak Kawsay são emblemáticos, a apontar uma nova possibilidade de convívio, a partir de crenças, de cosmovisões e de modelos mais próximos à raiz cultural de cada sociedade.

\footnotetext{
${ }^{15}$ La lección para la epistemología es ésta: no trabajar con conceptos estables. No eliminar la contrainducción. No dejarse seducir pensando que por fin hemos encontrado la descripción correcta de 'los hechos', cuando todo lo que ha ocurrido es que algunas categorías nuevas han sido adaptadas a algunas formas viejas de pensamiento, las cuales son tan familiares que tomamos sus contornos por los contornos del mundo mismo.
} 
Revisitar o Sumak Kawsay é buscar compreender a natureza sob uma ótica sistêmica, restabelecendo parâmetros outrora esquecidos. A constitucionalização de seus ideais indica que o sussurrar das vozes abafadas a sangue e suor enfim ganharam repercussão e ecoam inquietações e conclamações. Traz, sem duvida, possibilidades de entrever outros caminhos, encontrar outras respostas e compreender as comunidades em sua singularidade e particularidade.

\section{REFERÊNCIAS}

ACOSTA, Alberto. Bitácora Constituyente: ¡Todo para la Patria, nada para nosotros!. Quito: Ediciones Abya-Yala, 2008.

ACOSTA, Alberto; MARTINEZ, Esperanza. El buen vivir: Una vía para el desarrollo. Quito: Ediciones Abya-Yala, 2009.

BARRACHO, Carlos. Lições de psicologia Económica. Lisboa: Instituto Piaget, 2001.

BELLO, Álvaro. Etnicidad y ciudadanía en América Latina - La acción colectiva de los pueblos indígenas. Santiago do Chile: United Nations, CEPAL, 2004.

BENNETT, Wendell C. The andean highlands: an introduction. In: STEWARD, Julian H. (ed.). Handbook of south american indians. Vol. 2. The andean civilizations. Nova lorque: Cooper Square Publishers, 1963.

BOFF, Leonardo. Ecologia: grito da Terra, grito dos pobres. São Paulo: Ática, 1999.

CAVALCANTI, Clóvis. Meio Ambiente, Desenvolvimento Sustentável e Politicas Públicas. São Paulo: Cortez, 1997.

CHIVI VARGAS, Idón M. Os caminhos da descolonização na América Latina: os povos indígenas e o igualitarismo jurisdicional na Bolívia. In: VERDUM, Ricardo (Org.). Povos indígenas: constituições e reformas políticas na América Latina. Brasília: IES, 2009.

CUNHA, Paulo Ferreira da. Do constitucionalismo global. Revista Brasileira de Direito Constitucional - RBDC, n. 15, jan./jun. 2010, p. 245-255.

DALMAU, Rúben Martínez. El nuevo constitucionalismo latinoamericano y el proyecto de Constitución del Ecuador de 2008. Revista Alter Justicia: Estudios sobre teoría y justicia constitucional, ano 2, n. 1, p. 13-28, out. 2008a. 
DALMAU, Rúben Martínez. El Proyecto de constitución de Ecuador como último ejemplo del nuevo constitucionalismo latinoamericano. Entre Voces: Revista del Grupo Democracia y Desarrollo, Quito, n. 15, p. 67-71, ago./set. 2008b.

DAVALOS, Pablo. Movimiento indígena ecuatoriano: construcción política y epistémico. In: MATO, Daniel. Cultura, política y sociedad - Perspectivas latinoamericanas. Buenos Aires: CLACSO, 2005.

EQUADOR. Secretaría Nacional de Planificación y Desarrollo. Plan Nacional para el Buen Vivir 2009-2013: Construyendo un Estado Plurinacional e Intercultural. Quito: SENPLADES, 2009. Disponível em:

$<$ http://www.planificacion.gob.ec/wpcontent/uploads/downloads/2012/07/Plan_Nacional_para_el_Buen_Vivir.pdf $>$. Acesso em: 14 fev. 2014.

EQUADOR. Secretaría Nacional de Planificación y Desarrollo. Los nuevos retos de américa latina: socialismo y sumak kawsay. 1 ed. Quito: SENPLADES, 2010 (Colección Memorias, n. 1). Disponível em:

$<$ http://latinoamericana.org/2012/info/docs/SocialismoYSumakKawsay.pdf $>$. Acesso em: 14 fev. 2014.

EQUADOR. Secretaría Nacional de Planificación y Desarrollo. Plan Nacional para el Buen Vivir 2013-2017: Construyendo un Estado Plurinacional e Intercultural. Quito: SENPLADES, 2013. Disponível em: $<$ http://www.buenvivir.gob.ec/documents/10157/96c82f1c-5dd8-4a60-8283d95d9ed24f0e >. Acesso em 14 fev. 2014.

FEYERABEND, Paul. Contra el método. Barcelona: Ariel, 1981.

GALEANO, Eduardo. Las palabras andantes. Buenos Aires: Siglo XXI, 1994.

GALEANO, Eduardo. Las venas abiertas de America Latina. Madrid: Sigo XXI, 2001.

GUATTARI, Felix. Le trois écologies. Paris: Éditions Galilée, 1989.

HERCULANO, Selene C. Do desenvolvimento (in)suportável à sociedade feliz. In: GOLDENBERG, Miriam (Org.). Ecologia, ciência e política: participação social, interesses em jogo e luta de idéias no movimento ecológico. Rio de Janeiro:

Revan, 1992.

HOBSBAWM, Eric. En torno a los origenes de la revolución industrial. Madrid: Siglo XXI, 1980.

HOBSBAWM, Eric. The Invention of Tradition. Cambridge: Terence Ranger, 1983.

ILLICH, Ivan. La convivencialidad. Tradução de Matea P. De Gossmann. Barcelona: Barral Editores, 1974. 
LANDER, Edgardo (org.). A colonialidade do saber: eurocentrismo e ciências sociais - perspectivas latino-americanas. Buenos Aires: CLACSO, set. 2005.

LATOUCHE, Serge. Survivre au développement: De la décolonisation de l'imaginaire économique à la construction d'une société alternative. Paris: Mille et Une Nuits, 2004.

LAYRAGUES, Philippe. Do Ecodesenvolvimento ao Desenvolvimento Sustentável: evolução de um conceito? Revista Proposta, Rio de Janeiro, n. 71, p. 5-10, fev. 1997.

LEÓN, Magdalena. Cambiar la economía para cambiar la vida. In: ACOSTA, Alberto; MARTINEZ, Esperanza. El buen vivir: Una vía para el desarrollo. Quito: Ediciones Abya-Yala, 2009.

NAESS, Arne. Deep Ecology. In: MERCHANT, Carolyn. Key Concepts in Critical Theory: Ecology. Atlantic Highlands: Humanities Press, 1994.

QUIJANO, Aníbal. Colonialidad y Modernidad-racionalidad. In: BONILLO, Heraclio (comp.). Los conquistados. Bogotá: Tercer Mundo Ediciones, FLACSO, 1992.

RIBEIRO, W. C. et al. Desenvolvimento Sustentável: Mito ou Realidade? Revista Terra Livre, AGB, no 11-12, São Paulo: ago. 1992/93, p. 91-101.

SANTOS, Boaventura de Souza. A crítica da Razão Indolente: contra o desperdício da experiência. São Paulo: Cortez, 2000.

SANTOS, Boaventura de Sousa. Reconhecer para libertar - Os caminhos do cosmopolitismo cultural. Porto: Afrontamento, 2004.

SANTOS, Boaventura de Sousa. Refundación del Estado en América Latina: perspectivas desde una epistemología del Sur. Lima: Instituto Internacional de Derecho y Sociedad, 2010.

SARMENTO, Daniel. Neoconstitucionalismo no Brasil: riscos e possibilidades. In: SARMENTO, Daniel. Por um constitucionalismo inclusivo: história Constitucional Brasileira, Teoria da Constituição e Direitos Fundamentais. Rio de Janeiro: Lumen Juris, 2010.

THIELEN, Helmut. Além da Modernidade - para a globalização de uma esperança conscientizada. Rio de Janeiro: Vozes, 1998.

VIZENTINI, Paulo. A história do século XX. Porto Alegre: Novo Século, 1998.

WALLERSTEIN, Immanuel Maurice. European Universalism: The Rhetoric of Power. London: New Press, 2006. 
WOLKMER, Antonio Carlos; FAGUNDES, Lucas Machado. Tendências contemporâneas do constitucionalismo latino-americano: Estado plurinacional e pluralismo jurídico. Revista Pensar: Fortaleza, v. 16, n. 2, p. 371-408, jul./dez. 2011. 